\title{
Nuclear Microsatellite Primers for the Endangered Relict Fir, Abies pinsapo (Pinaceae) and Cross-Amplification in Related Mediterranean Species
}

\author{
Jose M. Sánchez-Robles ${ }^{1}{ }^{\text {** }}$, Francisco Balao ${ }^{1}$, Juan L. García-Castaño ${ }^{1}$, Anass Terrab ${ }^{1}$, \\ Laura Navarro-Sampedro ${ }^{2}$ and Salvador Talavera ${ }^{1}$
}

1 Departamento de Biología Vegetal y Ecología, Universidad de Sevilla, Apdo. 1095, Sevilla E-41080, Spain; E-Mails: fbalao@us.es (F.B.); jlgc@us.es (J.L.G.-C.); anass@us.es (A.T.); stalavera@us.es (S.T.)

2 Centro de Investigación, Tecnología e Innovación (CITIUS), Universidad de Sevilla, Apdo. 1095, Sevilla E-41080, Spain; E-Mail: lauranavarro@us.es

* Author to whom correspondence should be addressed; E-Mail: jsanchez15@us.es; Tel.: +34-954-559-887; Fax: +34-954-557-051.

Received: 5 September 2012; in revised form: 17 October 2012 / Accepted: 26 October 2012 / Published: 5 November 2012

\begin{abstract}
Twelve nuclear microsatellite primers (nSSR) were developed for the endangered species Abies pinsapo Boiss. to enable the study of gene flow and genetic structure in the remaining distribution areas. Microsatellite primers were developed using next-generation sequencing (454) data from a single Abies pinsapo individual. Primers were applied to thirty individuals from the three extant localities. The number of alleles per locus ranged from one to four. Cross-amplification was tested for other Abies species from the Mediterranean Basin, and most of the loci showed higher polymorphisms in the Mediterranean species than in A. pinsapo. These microsatellite markers provide tools for conservation genetic studies in Abies pinsapo as well other Abies species from the Mediterranean Basin.
\end{abstract}

Keywords: Abies; genetic conservation; mediterranean basin; nSSR; Pinaceae; population genetics 


\section{Introduction}

Abies pinsapo Boiss. is a tertiary relict fir species, endemic to three localities in southern Spain: Sierra de Grazalema Natural Park, Sierra de las Nieves Natural Park and the Sierra Bermeja Natural Area. Listed as an endangered species by the International Union for Conservation of Nature (IUCN), A. pinsapo forms woodlands that have a special ecological importance for many organisms [1]. Their current limited range makes them highly vulnerable to disturbance [2].

There are a few genetic studies focused on Abies pinsapo [3-6] but none used nuclear DNA molecular markers. Nuclear microsatellites (nSSR) are highly polymorphic markers, codominant and usually selectively neutral, making them suitable for the analysis of small-scale genetic diversity [7]. Previous authors have developed primers for nSSR in others Abies species, amplifying some of them in Abies pinsapo [8,9]. In this study, we report the isolation and characterization of 12 nuclear microsatellites by the efficient and quick 454 sequencing technique. Primers developed for these markers were applied in individuals from the three main mountain areas that encompass the whole distribution range. Additionally, these markers were evaluated in the 11 remaining Abies species from the Mediterranean Basin.

\section{Results and Discussion}

\subsection{Primers for Abies pinsapo}

Twelve high-quality loci were tested in 30 individuals from the three Abies pinsapo populations studied (Table 1). Three of them (Pin14, Pin22 and Pin25) were monomorphic. The number of alleles in the polymorphic loci ranged from two to five (mean \pm SE: $2.074 \pm 0.150$ ). Their observed and expected heterozygosities $\left(H_{\mathrm{o}}\right.$ and $\left.H_{\mathrm{e}}\right)$ ranged both from 0.100 to 0.600 . Null allele frequency $\left(N_{\mathrm{a}}\right)$ ranged from 0.000 to 0.907 . After Bonferroni correction for multiple comparisons (adjusted $\alpha=0.002$ ), no locus showed a significant deviation from expectations under Hardy-Weinberg equilibrium (HWE) and no linkage disequilibrium (LD) was detected for the 36 paired loci comparisons (Table 2).

Table 1. Details of 12 novel microsatellite primers developed in Abies pinsapo.

\begin{tabular}{|c|c|c|c|c|c|c|}
\hline Locus & Primer sequences $\left(5^{\prime}-3^{\prime}\right)^{a}$ & $\begin{array}{l}\text { Repeat } \\
\text { motif }\end{array}$ & $\begin{array}{l}\text { Size } \\
\text { (bp) }\end{array}$ & $\begin{array}{c}T_{\mathrm{a}} \\
\left({ }^{\circ} \mathbf{C}\right)\end{array}$ & $N_{\mathrm{a}}$ & $\begin{array}{c}\text { GenBank } \\
\text { Accession } \\
\text { No. }\end{array}$ \\
\hline Pin8 & $\begin{array}{l}\text { F: } \$ \text { TGATTTATCCTTCGGTCTTG } \\
\text { R: *AAAGGGCTATGTTTGAATTG }\end{array}$ & & & 50 & 3 & JX473825 \\
\hline $\operatorname{Pin} 14$ & $\begin{array}{l}\text { F: } \text { \#CAAATGTTGCAATGTAGGAC } \\
\text { R: *CGAATATCTTGCTAGTTGTC }\end{array}$ & $(\mathrm{AGA}) 8$ & 249 & 50 & 1 & JX473826 \\
\hline $\operatorname{Pin} 17$ & $\begin{array}{l}\text { F: \$TCCGATCCAATAGAAGATTC } \\
\text { R: *AAAGGTTGAATCAATGATCC }\end{array}$ & (ATTC)8 & 428 & 50 & 2 & JX473827 \\
\hline $\operatorname{Pin} 20$ & $\begin{array}{c}\text { F: } \$ \text { ATACAGTTATTGGCGACTCC } \\
\text { R:*GTGAGGCGTGTGTACAATC }\end{array}$ & (CATA) 8 & 296 & 50 & 4 & JX473828 \\
\hline $\operatorname{Pin} 22$ & $\begin{array}{l}\text { F: *GAGTCACATGCTTTGGTGAG } \\
\text { R: †TACCACTCAAGGCCATTAC }\end{array}$ & $(\mathrm{CAT}) 7$ & 108 & 50 & 1 & JX473829 \\
\hline $\operatorname{Pin} 25$ & $\begin{array}{l}\text { F: ICCCTAATTCAATGCAATTATC } \\
\text { R: *GCATCCTGTAGAGCAACTTG }\end{array}$ & $(\mathrm{TATG}) 8$ & 167 & 50 & 1 & JX473830 \\
\hline
\end{tabular}


Table 1. Cont.

\begin{tabular}{|c|c|c|c|c|c|c|}
\hline Locus & Primer sequences $\left(5^{\prime}-3^{\prime}\right)^{a}$ & $\begin{array}{l}\text { Repeat } \\
\text { motif }\end{array}$ & $\begin{array}{l}\text { Size } \\
\text { (bp) }\end{array}$ & $\begin{array}{c}T_{\mathrm{a}} \\
\left({ }^{\circ} \mathbf{C}\right)\end{array}$ & $N_{\mathrm{a}}$ & $\begin{array}{c}\text { GenBank } \\
\text { Accession } \\
\text { No. }\end{array}$ \\
\hline $\operatorname{Pin} 29$ & $\begin{array}{l}\text { F: } \$ \text { TGATTTATCCTTCGGTCTTG } \\
\text { R: *AAAGGGCTATGTTTGAATTG }\end{array}$ & $(\mathrm{CTT}) 11$ & 257 & 50 & 2 & JX473831 \\
\hline $\operatorname{Pin} 32$ & $\begin{array}{l}\text { F: †CAGCCCAAATAATTCTCTTC } \\
\text { R: *TAGCCTTTCTTGATGGAGAG }\end{array}$ & $(\mathrm{CAT}) 7$ & 254 & 50 & 2 & JX473832 \\
\hline $\operatorname{Pin} 44$ & $\begin{array}{l}\text { F: *GAACGATACCATTGCATCTC } \\
\text { R: } † \text { ACATGCTTTCTATTTCCAATC }\end{array}$ & (AC) 11 & 138 & 50 & 2 & JX473833 \\
\hline $\operatorname{Pin} 48$ & $\begin{array}{l}\text { F: *CCATGGACTTCGGTAATATC } \\
\text { R: †TCATGACAACAAGCGAGAAC }\end{array}$ & (GT) 10 & 189 & 50 & 5 & JX473834 \\
\hline Pin49 & $\begin{array}{l}\text { F: †AAGCTGGATAATGAAAGGAC } \\
\text { R: *GCAAATTGGTCTTTAACTCC }\end{array}$ & (AG) 10 & 173 & 50 & 2 & JX473835 \\
\hline Pin52 & $\begin{array}{l}\mathrm{F}: \text { \#AACACCAGGCATTCACATC } \\
\text { R: *ACTAGCTAAGCAACCACCTC }\end{array}$ & (CA) 11 & 274 & 50 & 2 & JX473836 \\
\hline
\end{tabular}

Note: $\mathrm{F}=$ forward primer; $\mathrm{R}=$ reverse primer; $T_{\mathrm{a}}=$ annealing temperature; $N \mathrm{a}=$ number of alleles;

a * indicates GTTT tag; $\dagger$ indicates CAG tag (5'-CAGTCGGGCGTCATCA-3'), $\$$ indicates M13R tag (5'-GGAAACAGCTATGACCAT-3').

Table 2. Results of primer screening in three Abies pinsapo populations.

\begin{tabular}{cccccccccccccccccc}
\hline & \multicolumn{4}{c}{ Sierra de las Nieves $(\boldsymbol{N}=\mathbf{1 0})$} & \multicolumn{4}{c}{ Grazalema $(\boldsymbol{N}=\mathbf{1 0})$} & & \multicolumn{5}{c}{ Sierra Bermeja $(\boldsymbol{N}=\mathbf{1 0})$} \\
\hline Locus & $A$ & $H_{\mathrm{o}}$ & $H_{\mathrm{e}}$ & $\mathrm{HWE}$ & $A_{\mathrm{n}}$ & $A$ & $H_{\mathrm{o}}$ & $H_{\mathrm{e}}$ & $\mathrm{HWE}$ & $A_{\mathrm{n}}$ & $A$ & $H_{\mathrm{o}}$ & $H_{\mathrm{e}}$ & $\mathrm{HWE}$ & $A_{\mathrm{n}}$ \\
Pin8 & 2 & 0.400 & 0.442 & 0.880 & 0.024 & 2 & 0.100 & 0.479 & 0.014 & 0.640 & 3 & 0.500 & 0.416 & 0.774 & 0.000 \\
Pin14 & 1 & 0.000 & 0.000 & - & - & 1 & 0.000 & 0.000 & - & - & 1 & 0.000 & 0.000 & - & - \\
Pin17 & 1 & 0.000 & 0.000 & - & - & 1 & 0.000 & 0.000 & - & - & 2 & 0.100 & 0.100 & 0.868 & 0.000 \\
Pin20 & 3 & 0.300 & 0.416 & 0.667 & 0.128 & 2 & 0.000 & 0.189 & 0.002 & 0.907 & 1 & 0.000 & 0.000 & - & - \\
Pin22 & 1 & 0.000 & 0.000 & - & - & 1 & 0.000 & 0.000 & - & - & 1 & 0.000 & 0.000 & - & - \\
Pin25 & 1 & 0.000 & 0.000 & - & - & 1 & 0.000 & 0.000 & - & - & 1 & 0.000 & 0.000 & - & - \\
Pin29 & 2 & 0.400 & 0.442 & 0.880 & 0.024 & 2 & 0.100 & 0.479 & 0.014 & 0.640 & 2 & 0.500 & 0.395 & 0.292 & 0.000 \\
Pin32 & 1 & 0.000 & 0.000 & - & - & 1 & 0.000 & 0.000 & - & - & 2 & 0.200 & 0.442 & 0.098 & 0.355 \\
Pin44 & 2 & 0.600 & 0.505 & 0.429 & 0.000 & 2 & 0.400 & 0.337 & 0.429 & 0.000 & 2 & 0.400 & 0.526 & 0.527 & 0.111 \\
Pin48 & 4 & 0.400 & 0.600 & 0.640 & 0.192 & 3 & 0.500 & 0.542 & 0.179 & 0.000 & 4 & 0.500 & 0.432 & 0.981 & 0.000 \\
Pin49 & 2 & 0.300 & 0.479 & 0.281 & 0.205 & 2 & 0.500 & 0.521 & 0.975 & 0.000 & 2 & 0.400 & 0.337 & 0.429 & 0.000 \\
Pin52 & 2 & 0.100 & 0.100 & 0.868 & 0.000 & 2 & 0.200 & 0.189 & 0.725 & 0.000 & 2 & 0.200 & 0.442 & 0.098 & 0.355 \\
\hline
\end{tabular}

Note: $N=$ simple size; $A=$ number of alleles; $H_{\mathrm{o}}=$ observed heterozygosity; $H_{\mathrm{e}}=$ expected heterozygosity; $A_{\mathrm{n}}=$ null allele frequency; HWE $=$ Hardy-Weinberg equilibrium test ( $p$-values).

\subsection{Cross-Amplification in Other Mediterranean Abies Species}

Primer amplifications in other Mediterranean Abies species were successful in most cases. Seven primers amplified in all species, Pin 8 did not amplify in any of them and the remaining four amplified at least in three species. For several loci, there was a lower number of alleles in A. pinsapo than in the other Mediterranean species, in spite of using fewer individuals for the latter (three individuals in A. nebrodensis and five individuals in the rest of them); see Table 3. This low number of alleles in Abies pinsapo could be due to a low effective population size [10]. 
Table 3. Screening of primers developed in Abies pinsapo in the 11 remaining Abies species from the Mediterranean Basin.

\begin{tabular}{|c|c|c|c|c|c|c|c|c|c|c|c|c|c|c|c|c|c|c|c|c|c|c|}
\hline \multirow{2}{*}{ Species } & \multicolumn{2}{|c|}{ Pin14 } & \multicolumn{2}{|c|}{ Pin17 } & \multicolumn{2}{|c|}{$\operatorname{Pin} 20$} & \multicolumn{2}{|c|}{$\operatorname{Pin} 22$} & \multicolumn{2}{|c|}{$\operatorname{Pin} 25$} & \multicolumn{2}{|c|}{ Pin29 } & \multicolumn{2}{|c|}{ Pin32 } & \multicolumn{2}{|c|}{ Pin44 } & \multicolumn{2}{|c|}{$\operatorname{Pin} 48$} & \multicolumn{2}{|c|}{ Pin49 } & \multicolumn{2}{|c|}{ Pin52 } \\
\hline & $P$ & $A$ & $P$ & $A$ & $P$ & $A$ & $P$ & $A$ & $P$ & $A$ & $P$ & $A$ & $P$ & $A$ & $P$ & $A$ & $P$ & $A$ & $P$ & $A$ & $P$ & $A$ \\
\hline & $(0 / 5)$ & - & & 1 & & 1 & & & & & & & & & $(5 / 5)$ & & & & & & & 1 \\
\hline A. boisil & & 1 & & 3 & & 5 & & 2 & & & & & & & & & & & & & & 5 \\
\hline A. bornmu & $(0 / 5$ & - & $(0 / 5)$ & - & $(5 / 5$ & 2 & & 1 & & & & 2 & & 1 & $(5 /$ & 2 & & & & & & 4 \\
\hline & $(0 / 5)$ & - & & - & $(5 / 5$ & 3 & & 5 & & & & & & 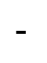 & & & & & & 3 & & 4 \\
\hline & $(0 / 5)$ & - & $(1 / 5)$ & 1 & $(5 / 5)$ & 1 & $(0 / 5)$ & - & $(5 / 5)$ & 3 & $(5 / 5)$ & 2 & $(0 / 5)$ & - & $(5 / 5)$ & 1 & $(5 / 5)$ & 7 & $(5 / 5)$ & 1 & 5) & 4 \\
\hline A. equi-trojani & $(0 / 5)$ & - & $(1 / 5)$ & 1 & $(5 / 5)$ & 3 & $(5 / 5)$ & 3 & $(5 / 5)$ & 2 & $(4 / 5)$ & 3 & $(0 / 5)$ & - & $(5 / 5)$ & 2 & $(5 / 5)$ & & $(5 / 5)$ & & $(5 /$ & 5 \\
\hline A. marocana & $(4 / 5)$ & 2 & $(1 / 5)$ & 1 & $(5 / 5)$ & 3 & & 4 & & 1 & & 3 & & 2 & & 2 & & & & & & 2 \\
\hline A. nebrodensis & $(0 / 3)$ & - & $(0 / 3)$ & - & $(3 / 3)$ & 1 & $(1 / 3)$ & 1 & $(3 / 3)$ & 2 & $(3 / 3)$ & 2 & $(3 / 3)$ & 3 & $(3 / 3)$ & 2 & $(3 / 3)$ & 1 & $(3 / 3)$ & 2 & $(3 / 3)$ & 3 \\
\hline A. nordmanniana & $(0 / 5)$ & - & $(0 / 5)$ & - & $(5 / 5)$ & 2 & $(0 / 5)$ & - & $(5 / 5)$ & 4 & $(4 / 5)$ & 3 & $(0 / 5)$ & - & $(5 / 5)$ & 3 & $(5 / 5)$ & & $(5 / 5)$ & & $(5 / 5)$ & 5 \\
\hline A. numidica & $(4 / 5)$ & 1 & $(4 / 5)$ & 2 & $(3 / 5)$ & 3 & $(0 / 5)$ & - & $(5 / 5)$ & 3 & $(1 / 5)$ & 1 & $(4 / 5)$ & 1 & $(5 / 5)$ & 2 & $(5 / 5)$ & 4 & $(5 / 5)$ & 2 & $(3 / 5)$ & 2 \\
\hline
\end{tabular}

Note: $P=$ number of individuals that amplified in the sample; $A=$ number of alleles. 


\section{Experimental Section}

\subsection{DNA Extraction, 454 Sequencing and Microsatellite Discovery}

Genomic DNA was extracted from leaf tissue from a single Abies pinsapo individual using a QIAGEN DNeasy Plant Mini Kit (QIAGEN, Valencia, CA, USA). A size selected DNA library was built and enriched for microsatellites using Dynabeads, as by Glenn and Schable [11] and sequenced on a 454 Genome Sequencer FLX System (454 Life Sciences, a Roche company, Branford, CT, USA) at the Savannah River Ecology Laboratory (Aiken, SC, USA). The 454 sequencing technique is described in detail in Abdelkrim et al. [12] and Lance et al. [13]. Development of microsatellites via "next generation sequencing" can be quicker, cheaper and it recovers more loci than enrichment methods. Moreover, this technique is more suitable for this purpose because of the large average size of the fragments obtained, which facilitates primer design [14]. CAP3 [15] was used to assemble sequences at $98 \%$ sequence identity using a minimal overlap of $75 \mathrm{bp}$. Sequence data were screened for di-, tri- and tetra-nucleotide repeats using the program MSATCOMMANDER version 0.8.1 [16] with minimum repeats set to eight, seven and six respectively, and primers were designed with Primer3 [17]. Two default 5'-tails (CAG: 5'-CAGTCGGGCGTCATCA-3' and M13R: 5'-GGAAA CAGCTATGACCAT-3') options were considered for designed primers, as with Faircloth [16], to allow a cheaper labeling technique than the direct labeling of the primers [18], as the inclusion of the 5 '-tail allows the use of a third primer in the polymerase chain reaction (PCR) (M13R or CAG) that is fluorescently labeled for detection in the DNA Analyzer sequencer [19]. Additionally, a not-tagged primer from a primer pair was designed with a 5'-GTTT tail to promote adenylation and thus facilitate genotyping [20]. Primers could be designed for 497 of the 3617 sequences obtained. Out of these 497 primer pairs, we removed 196 with low quality (i.e., redundant, and with high likelihood of forming secondary structures such as hairpins and self or primer dimers). Therefore 301 primers with high quality were selected.

\subsection{Primer Amplification and Quality Test}

Preliminary screenings from 50 loci (out of the 301 selected) were done to test the amplification quality using two previously obtained high quality DNA samples. Of these, 31 loci amplified well, but 19 primer pairs produced unclear patterns in the electropherograms. Conditions for PCR amplification were an initial denaturation step of $5 \mathrm{~min}$ at $94{ }^{\circ} \mathrm{C}$, followed by five cycles of $94{ }^{\circ} \mathrm{C}$ for $30 \mathrm{~s}, 60{ }^{\circ} \mathrm{C}$ for $30 \mathrm{~s}$, and $72{ }^{\circ} \mathrm{C}$ for $30 \mathrm{~s} ; 21$ cycles of $94{ }^{\circ} \mathrm{C}$ for $30 \mathrm{~s}, 60{ }^{\circ} \mathrm{C}$ for $30 \mathrm{~s}$ (decreased by $0.5{ }^{\circ} \mathrm{C}$ per cycle), and $72{ }^{\circ} \mathrm{C}$ for $30 \mathrm{~s} ; 15$ cycles of $94{ }^{\circ} \mathrm{C}$ for $30 \mathrm{~s}, 50{ }^{\circ} \mathrm{C}$ for $30 \mathrm{~s}$ and $72{ }^{\circ} \mathrm{C}$ for $30 \mathrm{~s}$; and a final step of $8 \mathrm{~min}$ at $72{ }^{\circ} \mathrm{C}$. PCR reactions were carried out using approximately $50 \mathrm{ng}$ of genomic DNA in a total volume of $20 \mu \mathrm{L}$, containing $2 \mu \mathrm{L}$ of PCR Buffer $1 \times\left(0.2 \mathrm{mM} \mathrm{MgCl}_{2}\right), 2 \mu \mathrm{L}$ of dNTP $0.1 \mathrm{mM}$ ( $0.025 \mathrm{mM}$ each), $0.5 \mu \mathrm{L}$ of BSA $(0.025 \mathrm{mg} / \mathrm{mL}), 0.2 \mu \mathrm{L}$ of i-Start Taq DNA polymerase $(1 \mathrm{U} / \mu \mathrm{L})$ (iNtRON Biotecnology Inc., Sungnam, Korea), $1.25 \mu \mathrm{L}$ of primer with 5'-GTTT tail $(0.25 \mu \mathrm{M})$, $0.3 \mu \mathrm{L}$ of primer with 5 '-CAG or M13R tail $(0.06 \mu \mathrm{M})$ and $0.5 \mu \mathrm{L}$ of universal primer with 6-carboxyfluorescein (FAM), nitrobenzoxadiazolyl (NED), or VIC fluorescent label $(0.25 \mu \mathrm{M})$. PCR products were run on a 3730 DNA Analyzer sequencer (Applied Biosystem, Foster City, CA, USA) 
and sized with LIZ 500 standard (Applied Biosystem, Foster City, CA, USA). Fragments were analyzed using GENEMARKER version 1.8 (SoftGenetics, State College, PA, USA).

\subsection{Genotyping and Cross-Amplification}

Twelve high-quality loci were tested in 30 individuals, 10 from each of the three unique $A$. pinsapo localities (Sierra de Grazalema Natural Park, Sierra de las Nieves Natural Park, and Sierra Bermeja Natural Area). Cross-amplification tests for all loci were performed with the 11 remaining Abies species from the Mediterranean Basin (see Supplementary Information), using five samples per species across their distribution ranges (three individuals for the micro-endemic $A$. nebrodensis).

\subsection{Genetic Analyses}

Observed heterozygosity $\left(H_{\mathrm{o}}\right)$, expected heterozygosity $\left(H_{\mathrm{e}}\right)$, null allele frequency $\left(A_{\mathrm{n}}\right)$ and Hardy-Weinberg equilibrium test (HWE) were obtained for each locus and population in CERVUS 3.0.3 software [21]. A test for genotypic linkage disequilibrium was conducted with GENEPOP 4.0.10 software [22].

\section{Conclusions}

We present twelve nuclear microsatellite loci for the Spanish fir Abies pinsapo Boiss. These loci may be useful for conservation genetic studies and they will be used to improve our understanding of gene movement between the relict populations of this species. Information derived from genetic studies may contribute to the development of more effective plans for the recovery and management of this endangered species. Furthermore, since most of the primers developed for Abies pinsapo amplified successfully in the other Mediterranean Abies species, they are suitable for both intra- and inter-specific studies.

\section{Acknowledgments}

The authors thank P. Gibbs for helpful comments on the manuscript and M. Lorenzo for helpful advice in the laboratory. This study was supported by Junta de Andalucía (Proyecto de Excelencia P08-RNM-03703) and Ministerio de Educación y Ciencia de España (Flora iberica VIII; CGL2009-08178).

\section{References}

1. Arista, M.; Herrera, J.; Talavera, S. Biología del pinsapo (In Spanish); Junta de Andalucía, Consejería de Medio Ambiente: Andalusia, Spain, 1997.

2. Frankham, R; Ballou, J.D.; Briscoe, D.A. Introduction to Conservation Genetics; Cambridge University Press: New York, NY, USA, 2002; pp. 1-22.

3. Martín, M.A.; Álvarez, J.B.; Martín, L.M. Genetic diversity of Spanish fir (Abies pinsapo Boiss.) populations by means of megagametophyte storage proteins. Anna. For. Sci. 2010, 67, 1-7. 
4. Terrab, A; Talavera, S.; Arista, M.; Paun, O.; Stuessy, T.F.; Tremetsberger, K. Genetic diversity at chloroplast microsatellites (cpSSRs) and geographic structure in endangered West Mediterranean firs (Abies spp., Pinaceae). Taxon 2007, 56, 409-416.

5. García, F.J.; Pascual, L.; Perfectti, F. Diferenciación a Nivel Subespecífico de las Poblaciones Marroquíes de Abies pinsapo Boiss. Mediante un Estudio Enzimático (In Spanish). In Proceedings of Evaluación de los Recursos Genéticos, Pontevedra, Spain, 1993; pp. 195-199.

6. Pascual, L.; Garcia, F.J.; Perfectti, F. Estudio de la Variabilidad Genética en Poblaciones de Pinsapo (Abies pinsapo Boiss.) (In Spanish). In Proceedings of Evaluación de los Recursos Genéticos, Pontevedra, Spain, 1993; pp. 201-205.

7. Lefort, F.; Echt, C.; Streiff, R.; Vendramin, G.G. Microsatellite sequences: A new generation of molecular markers for forest genetics. For. Genet. 1999, 6, 15-20.

8. Hansen, O.; Vendramin, G.; Sebastiani, F.; Edwards, K. Development of microsatellite markers in Abies nordmanniana (Stev.) Spach and cross-species amplification in the Abies genus. Mol. Ecol. Notes 2005, 5, 784-787.

9. Cremer, E.; Liepelt, S.; Sebastiani, F.; Buonamici, A.; Mychalczyk, I.M.; Ziegenhagen, B.; Vendramin, G. Identification and characterization of nuclear microsatellite loci in Abies alba Mill. Mol. Ecol. Notes 2006, 6, 374-376.

10. Kimberly, A.S.; Toonen, R.J. Microsatellites for ecologists: A practical guide to using and evaluating microsatellite markers. Ecol. Lett. 2006, 9, 615-629.

11. Glenn, T.C.; Schable, N.A. Isolating microsatellite DNA loci. Methods Enzymol. 2005, 395, 202-222.

12. Abdelkrim, J; Roberston, B.C.; Stanton, J.L.; Gemmell, N.J. Fast, cost-effective development of species-specific microsatellite markers by genomic sequencing. BioTechniques 2009, 46, 185-192.

13. Lance, S.L.; Light, J.E.; Jones, K.L.; Hagen, C.; Hafner, J.C. Isolation and characterization of 17 polymorphic microsatellite loci in the kangaroo mouse, genus Microdipodops (Rodentia: Heteromyidae). Conserv. Genet. Resour. 2010, 2, 139-141.

14. Gardner, M.G.; Fitch, A.J.; Bertozzi, T.; Lowe, A.J. Rise of the machines-Recommendations for ecologists when using next generation sequencing for microsatellite development. Mol. Ecol. Res. 2011, 11, 1093-1101.

15. Huang, X.; Madan, A. CAP3: A DNA sequence assembly program. Genome Res. 1999, 9, 868-877.

16. Faircloth, B.C. Msatcommander: Detection of microsatellite repeat arrays and automated, locus-specific primer design. Mol. Ecol. Res. 2008, 8, 92-94.

17. Rozen, S.; Skaletsky, H.J. Primer3 on the WWW for General Users and for Biologist Programmers. In Bioinformatics Methods and Protocols: Methods in Molecular Biology; Krawetz, S., Misener, S., Eds.; Humana Press: Totowa, NJ, USA, 2000; Volume 132, pp. 365-386.

18. Schuelke, M. An economic method for the fluorescent labeling of PCR fragments. Nat. Biotechnol. 2000, 18, 233-234.

19. Boutin-Ganache, I.; Raposo, M.; Raymond, M.; Deschepper, C.F. M13-tailed primers improve the readability and usability of microsatellite analyses performed with two different allele-sizing methods. Biotechniques 2001, 31, 24-28. 
20. Brownstein, M.J.; Carpten J.D., Smith, J.R. Modulation of non-templated nucleotide addition by Taq DNA polymerase: Primer modifications that facilitate genotyping. Biotechniques 1996, 20, 1004-1010.

21. Kalinowski, S.T.; Taper, M.L.; Marshall, T.C. Revising how the computer program CERVUS accommodates genotyping error increases success in paternity assignment. Mol. Ecol. 2007, 16, 1099-1106.

22. Rousset, F. Genepop'007: A complete re-implementation of the GENEPOP software for Windows and Linux. Mol. Ecol. Res. 2008, 8, 103-106.

(C) 2012 by the authors; licensee MDPI, Basel, Switzerland. This article is an open access article distributed under the terms and conditions of the Creative Commons Attribution license (http://creativecommons.org/licenses/by/3.0/). 